\title{
EFORT: from its foundation to the present time
}

\author{
M. Freeman • W. Puhl
}

Published online: 8 May 2010

(C) EFORT 2010

EFORT was founded over the period 1989-1992. All those who were then European national society presidents or their representatives agreed to take this step in 1991 at a meeting in Marentino (Italy) arranged under the auspices of COCOMAC (Comitè de Coordination des Societès d'Orthopedie du Marchè Commun) The 20th anniversary of this meeting will be commemorated in 2011 in Copenhagen. We now provide an account of the founding events (originally described in the first EFORT Bulletin in 1994 (see the EFORT portal, www. efort.org and the December 2002 EFORT Bulletin)) followed by a short description of the events since then.

\section{The founding of EFORT 1989-1992}

At a meeting in New York on 4-8 April 1989, Michael Freeman (M.F.) conceived the idea that there should be a combined meeting of the European orthopaedic societies in spring 1993 in Paris - shortly after the date of the Single European Act.

On his return to the UK, M.F. discussed this possibility with Jacques Duparc (J.D.). J.D. thought the idea a good one and agreed to plan the meeting with SOFCOT, specifically with Bernhard Glorion, the 1993 President of SOFCOT. SOFCOT agreed to underwrite the costs and to cancel their normal autumn meeting in favour of the

\footnotetext{
W. Puhl $(\bowtie)$

Orthopädische Spezialklinik Oberstdorf,

Trettachstrasse 16,

87561 Oberstdorf, Germany

e-mail: Wolfhart.puhl@efort.org

M. Freeman

London, UK

e-mail: drfree@freenetname.co.uk
}

proposed spring combined meeting. (Erwin Morscher chaired the Scientific Committee.) A plan for a combined European meeting in Paris in 1993 now existed and SOFCOT formally cancelled their autumn meeting.

In a conversation between M.F. and Wolfhart Puhl (W.P.) in a DGOT meeting in Zurich on 1-2 August 1990, W.P. agreed to broach the idea of a combined meeting to DGOT and later obtained DGOT's agreement.

Early in 1991 M.F. telephoned Paolo Gallinaro (P.G.), then President of COCOMAC, to seek the agreement of Italy. The agreement of the UK (where M.F. was to be President of the BOA in 1993), France and Germany had already been obtained. M.F. proposed that the European national society presidents should meet to form a society which would then be responsible for a series of combined meetings (not just a single meeting, as then planned). P.G. suggested a venue under the auspices of COCOMAC: a villa in Marentino, near Turin.

The meeting of presidents, or their representatives, took place on 23 November 1991 in Marentino (see EFORT Bulletin December 2002). The host was P.G. and the Chairman for working sessions was M.F. (Fig. 1). It was decided that a federation of all the European national societies of orthopaedics and traumatology should be formed and called EFORT. Trauma was to be confined to musculoskeletal trauma; the members were to be the national societies; the language was to be English. A first draft of the statutes was written. A Steering Committee was created to move the project forward and M. F. was appointed as its chairman.

On April 251992 a meeting of the Steering Committee was hosted in Munich by DGOT (hosts W.P. and W. Pförringer). Eoghan Lavelle was appointed secretary to the committee and M.F. was confirmed as its chairman. This meeting finalised the Marentino draft statutes in principle 


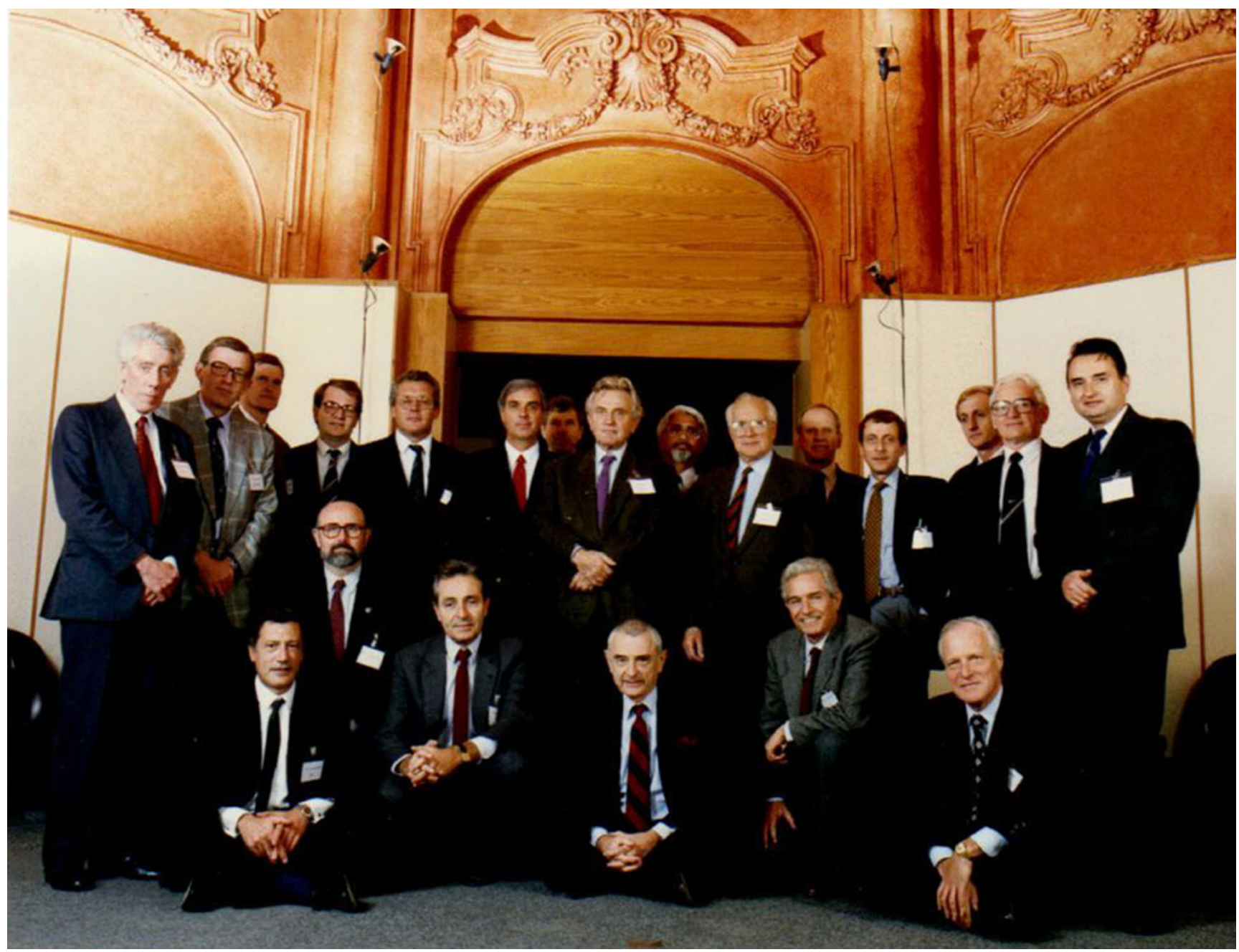

Fig. 1 The Marentino Working Group: Back row (heads only), left to right: Nikolaus Böhler (Austria), Lászlo Bucsi (Hungary), Andreas Burckhardt (Switzerland), Jim van Horn (Netherlands), Pär Slätis (Finland), Ludvig Fjeld Solheim (Norway). Middle row, left to right: Richard Bouillet (Secretary COCOMAC), Peter Frandsen (Denmark), Wolfgang Pförringer (Germany), Wolfhart Puhl* (Germany), Ivan Kempf (France), Jacques Duparc* (France), Roger Lemaire (Belgium), Eoghan Lavelle (Ireland),
Alexandru Pop (Romania) Seated, left to right: Paolo Gallinaro* (Italy, Host \& Chairman of COCOMAC), Luis Munuera Martinez (Spain), Ioannis Dimitriou (Greece), Michael Freeman* (UK, Working Group Chairman), Mario Randelli (Italy), Ian Goldie (representing Iceland and Sweden). Present but not in photo: Halldór Baldursson (Iceland), Szucli (Poland), Kubat (Czechoslovakia). Apologies for absence: Portugal. No record of presence: Bulgaria, Yugoslavia. *The "founding fathers" which were then refined in the course of telephone conversations between M.F. and others, particularly Peter Frandsen. The federation was legally registered in Munich, Germany on 15 October 1992 by W.P., but its domicile was later moved to the canton of Basle, Switzerland.

At a meeting of COCOMAC in November in Paris (with EFTA representatives, including Nikolaus Böhler and Erwin Morscher), it was agreed that COCOMAC should be wound up and that the funds of COCOMAC would be taken over by EFORT when it was founded. The Chairman of COCOMAC (P.G) and the permanent General Secretary of COCOMAC, Richard Bouillet, were in agreement with this step. At the same meeting DGOT offered to underwrite a second EFORT Congress in Germany in 1995.

The last meeting of the Steering Committee was held on 11 November in Paris. The proposal was made from the Chair (by M.F.), and accepted unanimously, that EFORT should be created with its agreed statutes and that J.D. should be the first President (for 1992 and 1993). M.F. was appointed Vice President; Eoghan. Lavelle, Secretary; P.G., Treasurer; and Peter Frandsen and Esteve de Miguel, members of the Executive Committee. 
EFORT and its first Executive Committee were now in existence.

\section{Achievements in the period 1993-2008}

In 1993 the General Assembly decided that EFORT should have the following four objectives (EFORT Bulletin 1994):

(1) To organize a scientific congress every 2 years

(2) To arrange instructional courses every 1-2 years

(3) To publish the instructional courses and various other materials

(4) To arrange the exchange of orthopaedic surgeons between European countries for training purposes, a task previously undertaken by COCOMAC

We now review the extent to which these goals have been attained.

\section{Scientific congresses}

Eight biennial scientific congresses have been arranged, starting in Paris in 1993 (Fig. 2). By the eighth congress the size of the attendance (see graph) had made it necessary to change to an annual event for congresses 9 and 10. Initially this had the effect of reducing participation at any one congress but of increasing the participation over a 2-year period (see Fig. 2). From the results shown in the graph, we conclude that our first objective has been achieved.

\section{Instructional courses}

The following courses have been arranged.

\begin{tabular}{|c|c|c|}
\hline Year & Place & Theme \\
\hline \multirow[t]{3}{*}{2006} & IC Geneva, University Hospital Geneva & Shoulder \\
\hline & IC Berlin Sommerfeld, Sana Klinik Sommerfeld & Knee \\
\hline & IC Zürich, Schulthess Klinik & Hip / knee \\
\hline \multirow[t]{3}{*}{2007} & IC Budapest, Uzsoki Hospital & Hip / knee \\
\hline & IC Zürich I, Schulthess Klinik & Shoulder \\
\hline & IC Zürich II, Schulthess Klinik & Hip / knee \\
\hline \multirow[t]{5}{*}{2008} & IC Edinburgh, Royal College of Surgeons & $\begin{array}{l}\text { General } \\
\text { orthopaedics }\end{array}$ \\
\hline & IC Budapest, Uzsoki Hospital & Hip / knee \\
\hline & IC Milan, Istituto Ortopedico Galeazi & Hip \\
\hline & IC Prague, Na Homolce Hospital & Spine \\
\hline & IC Ankara, Hacettepe University & Hip \\
\hline \multirow[t]{5}{*}{2009} & IC Budapest, Uzsoki Hospital & Hip / knee \\
\hline & IC Marseille, Hospital Sainte-Marguerite & Knee \\
\hline & IC Vienna, Orthopaedic Hospital Vienna Speising & Paediatrics \\
\hline & IC Milan, Istituto Ortopedico Galeazi & Hip \\
\hline & $\begin{array}{l}\text { ExMEx Barcelona, Hospital Principes d'España } \\
\text { Bellvitge }\end{array}$ & Spine \\
\hline \multirow[t]{4}{*}{2010} & ExMEx Bologna, Istituto Ortopedico Rizzoli & $\begin{array}{l}\text { Sports-related } \\
\text { injuries }\end{array}$ \\
\hline & IC Copenhagen, Bispbjerg Hospital & $\begin{array}{l}\text { Fractures in the } \\
\text { elderly }\end{array}$ \\
\hline & IC Vienna Orthopaedic Hospital Vienna Speising & Shoulder \\
\hline & IC Geneva, University Hospital Geneva & Foot and ankle \\
\hline 2010 & EFORT IC Lyon, Hôpital de la Croix-Rousse & Knee \\
\hline
\end{tabular}

Fig. 2 Scientific congresses

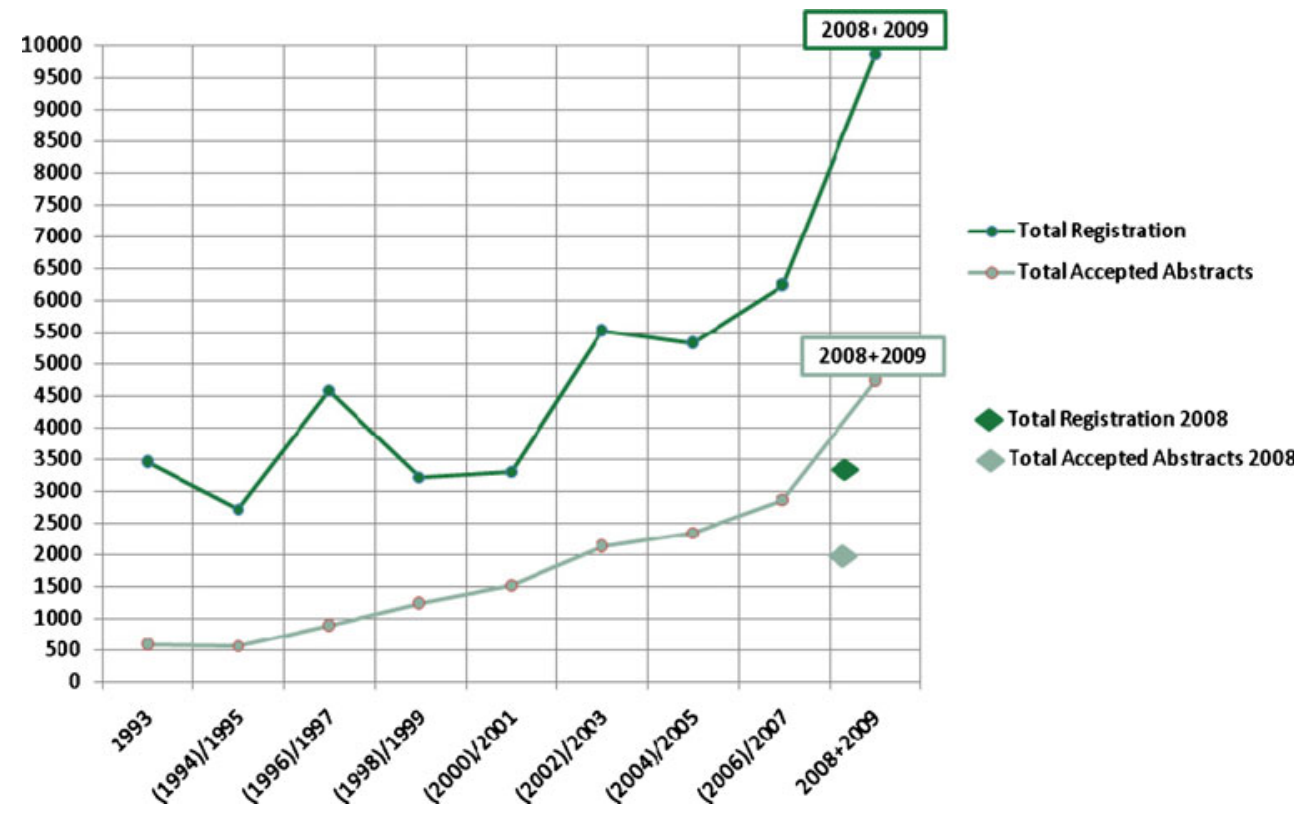




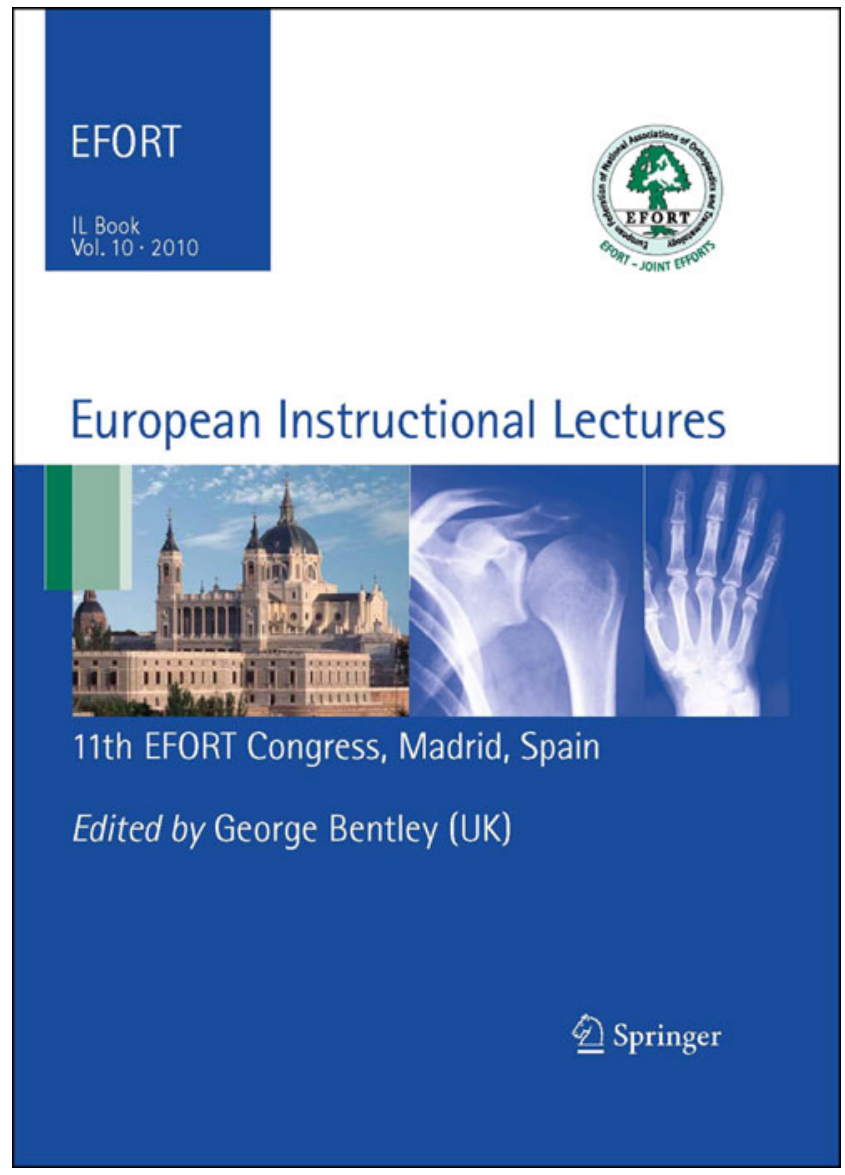

Fig. 3 Cover of the IL Book, Volume 10

\section{Publications}

Instructional Lecture Books

Since 1995 EFORT has published an Instructional Lecture book for each congress-10 IL books by 2010 .

Other material has been published during the last years such as the EUROHIP book.

The Journal European Orthopaedics and TraumatologyEOTR, the official journal of EFORT, will start at the EFORT Congress in Madrid, and a textbook is in process (Fig. 3).

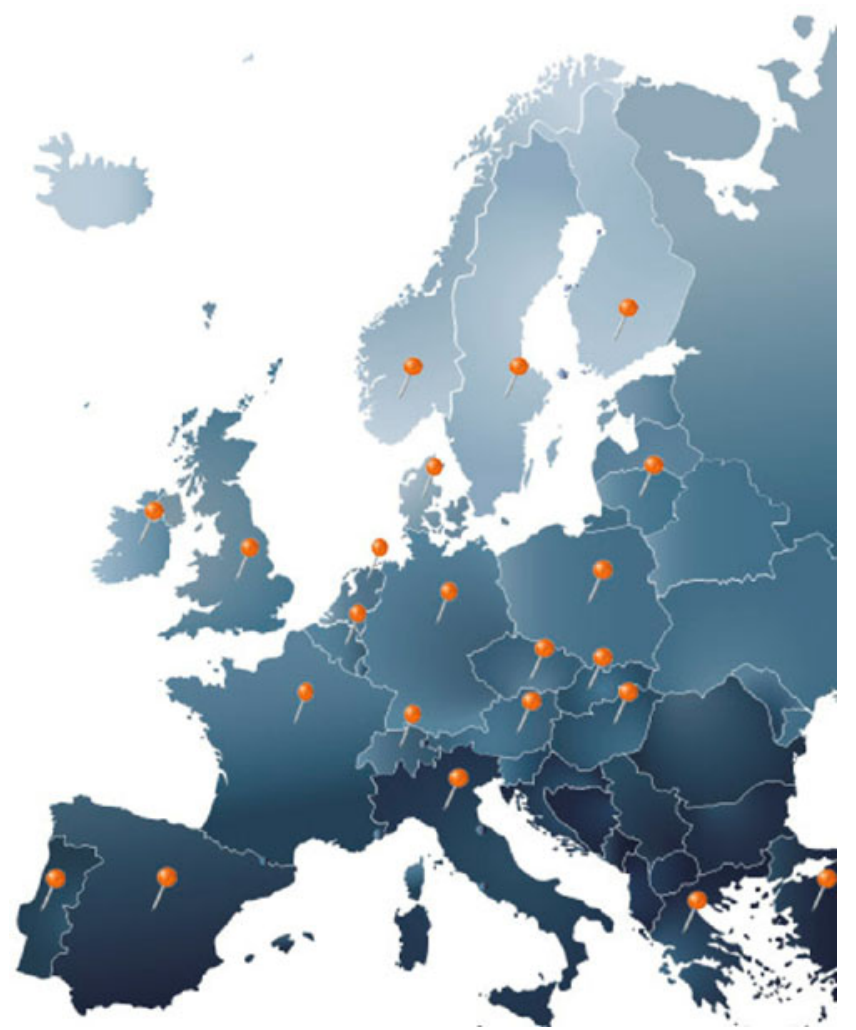

Fig. 4 Countries that have received travelling fellows

\section{Fellowships}

EFORT organises two kinds of fellowship:

1. Travelling fellowships: Since 1995, each spring and autumn EFORT has given young residents in their final year of orthopaedic training the opportunity to enhance their personal experience by observation, participation and discussion, as well as to visit other European countries. Each national society can nominate one fellow per year. Since the travelling fellowship programme was started in 1995, fellowships have been organised in 22 different countries (Fig. 4).

2. Visiting fellowships: The EFORT visiting fellowship allows young and active colleagues from the orthopaedic profession throughout Europe to spend a period of $2-$ 4 weeks in a clinic, department or institution of their own choice in another European country after finishing their orthopaedic training. Every year EFORT receives a large number of applications via the internet. 